\title{
Health institutions preparedness for emergency response
}

\author{
B Bhattarai, Head of Department, Department of Anaesthesiology and Critical Care \\ B.P. Koirala Institute of Health Sciences, Dharan, Nepal
}

Health institutions like hospitals, health centres, blood banks etc are important institutions for the public. But their importance is even better realized during emergencies and disasters when preserving life of each individual becomes the most important issue $^{1}$. During disasters these institutions coordinate and cooperate with other non-health sectors such as transport, water and sanitation, electricity, security etc to ensure their uninterrupted services.

Disasters and emergencies create massive workload to these institutions in the form of large volume of victims requiring emergency care and surgeries. In addition subsequent outbreaks of communicable diseases add heavily to the already overloaded systems ${ }^{2}$. These institutions, therefore, need to be not only robust in their physical structures and facilities but must also have scope of accommodating greater number of victims and patients in case of emergencies and disasters. During disaster times these institutions also serve as source of important information about the event in the form of details of the victims and possibility of outbreaks of communicable diseases.

In many developing countries including Nepal, health institutions do not fall on priority areas. Budgets are often limited without paying adequate attention to the need of robustness of their construction and reliability of their services they provide. As a consequence they also become victims of the disasters. In fact proper investments on health institutions are important and serious matter from the time of planning itself. Failure of health institutions in providing emergency services during a disaster can greatly affect public morale and a community's social and health capital ${ }^{3}$.

If the structure of the health institution gets damaged during disaster like earthquakes the consequences are grave for several reasons. First, these can cause injuries and even kill both the patients and health care providers inside the structures ${ }^{4}$. Second, the emergency care of the disaster victims is hindered as these institutions serve as the focal points of care during such events ${ }^{5}$. Whatever care is possible it will be diverted to the care of the occupants of the health institutions. Third, there is disruption of the regular care of the patients with acute and chronic illnesses. Moreover, the gathered crowd during such events further cripples the functionality of the institution. Fourth, damage or destruction of health institution in itself a 
huge economic loss as it leads to diversion of the limited resources for reconstruction of the structures that could have been spent on general public's other health activities.

We have recent experience of the Gorkha Earthquake 2015. This experience must prompt us to prepare ourselves to face the next impending disaster. There are many things we can do to prepare ourselves ${ }^{2}$. We can frame and implement national policies and plans to make our health facilities safer during emergencies and disasters. We can identify safe location for constructing health care facilities. We can assess and grade our existing health institutions in view of safety in the event of disasters. We can develop emergency response plan if already not existing and test and update them with appropriate drills and exercises. We can develop and strengthen our partnership with the community. Good disaster response plan and effective community participation are vital in mitigating the impacts of disasters ${ }^{6}$. The community is receptive for it with our recent experience. We can provide training to the healthcare providers and managers to respond to emergencies focusing on several important issues. These issues include human resource management, physical resource management, victims' management and transfer, nutrition management, mental health management, environmental consequences and management, inter- organizational co-ordination, technology and communication management etc ${ }^{7}$.

We must give shape to our equipment when the iron is hot. Undoubtedly, there is no better way of responding to emergencies and disasters other than preparedness.

\section{References}

1. Irmiter C, Subbarao I, Shah JN, Sokol $P$, James JJ. Personal Derived Health Information: A Foundation to Preparing the United States for Disasters and Public Health Emergencies. Disaster Med Public Health Preparedness 2012; 6: 303310

2. Disaster Risk Management for Health Fact Sheets. Disaster Risk Management for Health Safe Hospitals: Prepared for Emergencies And Disasters. WHO Global Platform, May 2011. Accessed from http://www.who.int/hac/events/drm_fa ct_sheet_safe_hospitals

3. Nia MS, Nafissi M, Moharamzad Y. Survey of Bam earthquake survivors' opinions on medical and health systems services. Prehosp Disaster Med. 2008;23(3):263-8

4. Milsten A. Hospital responses to acute-onset disaster: a review. Prehosp Disaster Med. 2000;15(1):3245 
5. Farmer JC, Carlton PK. Providing critical care during a disaster: the interface between disaster response agencies and hospitals. Crit Care Med. 2006; 34(3 Suppl):S56-59

6. Su TT, Saimy BI, Bulgiba AM. Socioeco-nomic consequences of the 2004 tsunami: Policy implications for natural disaster management. Am J Prev Med 2013; 57: 574-576

7. Pourhosseini SS, Ardalan A, Merholhassani $\mathrm{MH}$. Key aspects of providing health care services in disaster response stage. Iran J Public Health 2015; 44: 111-118 